\title{
Biochemical Analysis of Callus Tissue in Osteogenesis Imperfecta Type IV Evidence for Transient Overmodification in Collagen Types I and III
}

\author{
R. E. Brenner, ${ }^{\star}$ U. Vetter, ${ }^{\ddagger}$ A. Nerlich, ${ }^{5}$ O. Wörsdorfer," W. M. Teller," and P. K. Müller* \\ ${ }^{*}$ Max Planck Institut für Biochemie, 8033 Martinsried, Federal Republic of Germany; ${ }^{\ddagger}$ Zentrum für Kinderheilkunde, Abteilung I, der \\ Universität Ulm, 7900 Ulm, Federal Republic of Germany; ${ }^{\S}$ Pathologisches Institut der Ludwig Maximilians Universität, 8000 \\ München, Federal Republic of Germany; and "Abteilung Chirurgie III der Universität Ulm, 7900 Ulm, Federal Republic of Germany
}

\begin{abstract}
We analyzed tissue and cells from a stationary and a rapidly growing hyperplastic callus from a patient with osteogenesis imperfecta (OI) type IV and compared the results with those of compact bone and skin fibroblasts of an age-matched control.

Collagen and protein contents per cell were low in the callus tissues and collagen I and III were overmodified as evidenced by an elevated level of hydroxylysine. The degree of lysyl hydroxylation was highest in those regions that appeared most immature by histological examination. Lysyl hydroxylation approached normal levels in collagen from the stationary callus and from the center of the growing callus. Overmodification of collagen was not seen in compact bone or cell cultures (neither skin fibroblasts nor callus cells) from the patient. Elevation of hydroxylysine in collagen from OI patients is generally attributed to mutations that delay triple helix formation. Our observations suggest that the varying degree of collagen modifications may occur in consequence of regulatory mechanisms during bone development and tissue repair. These mechanisms may be defective in some patients with $\mathrm{OI}$ as seen in this case with hyperplastic callus formation.
\end{abstract}

\section{Introduction}

Osteogenesis imperfecta $(\mathrm{OI})^{1}$ comprises a group of inherited diseases of connective tissues and is characterized by fragile bones and severe skeletal deformations (1). Other tissues such as skin, sclerae, and teeth, all of which contain substantial proportions of collagen I, may also be affected (2). This disease has been divided into four subgroups according to clinical and genetic features (3). Furthermore, abnormalities in the production of collagen I as well as in its structure have been shown in OI cells and postulated to cause the clinical symptoms and to account for the clinical heterogeneity (4). Fibroblasts of some patients produce overhydroxylated and overglycosylated collagen I molecules, and in sporadic cases mutations in the $\alpha 1$ (I) or $\alpha 2$ (I) genes, respectively, have been found $(5,6)$. These observations led to the hypothesis that small mutations may

Address correspondence to Dr. P. K. Müller, Medizinische Universität zu Lübeck, Institut für Med. Molekularbiologie, Ratzeburger Allee 160, D-2400 Lübeck, FRG.

Received for publication 22 June 1988 and in revised form 8 March 1989.

1. Abbreviations used in this paper: OI, osteogenesis imperfecta.

J. Clin. Invest.

(c) The American Society for Clinical Investigation, Inc.

0021-9738/89/09/0915/07 \$2.00

Volume 84, September 1989, 915-921 cause a delay in triple helix formation, which in turn allows the modifying enzymes to act for an extended period on the individual collagen chains (7). On the other hand, there is experimental evidence that overmodification of collagen is a physiological feature of fetal bone development (8). One may assume that a defect in an as yet unknown control mechanism for collagen modification is alternatively responsible for an overmodified collagen molecule. Finally, there is convincing evidence that in some patients with OI, defects in proteins other than collagen, such as osteonectin, may represent contributory factors in the onset of this disease (9).

Fracture healing in OI is usually normal. Some patients, however, tend to develop a hyperplastic callus without any apparent bone fracture. This is a rare but characteristic complication in patients with OI type IV which can further restrict the physical activity of the patient (10-12). It is not known at present why patients with an osteopenic disease produce substantial amounts of osseous tissue, which in some ways can mimic the features of an osteosarcoma (13-16). A detailed investigation of callus formation in OI may, however, not only help to understand the molecular basis of this disease, but may also contribute to the elucidation of processes involved in fracture healing.

In the present study we analyzed a recurrent hyperplastic callus in its stationary and rapidly growing forms, both obtained from the same patient with OI type IV. Additionally, callus cells, skin fibroblasts, and bone compacta of the same patient were investigated and compared with an age-matched control.

\section{Methods}

Case report. Gestational and birth anamnesis were uneventful. OI type IV was diagnosed clinically at the age of $3 \mathrm{yr}$ after three consecutive tibial fractures within 4 mo. The typical radiographic appearance of the skeletal system and a bone biopsy confirmed the diagnosis. From 4 to $10 \mathrm{yr}$ the patient suffered from two to five fractures per year. At the age of $10 \mathrm{yr}$ he developed a hyperplastic callus after a spontaneous fracture of the distal metaphysis of the right femur. The deformed and bowed right femur was surgically corrected at the age of $15 \mathrm{yr}$ and stabilized by an intramedullary rod. At the same time the stationary callus was removed. $10 \mathrm{~d}$ after the operation a new hyperplastic callus developed at the site of the proximal osteotomy close to the hip joint. Since the mobility of the right hip joint was impaired, this rapidly growing hyperplastic callus was again surgically removed but reappeared within $2 \mathrm{wk}$. At present this callus shows a slow regression.

Morphological examination. For histological examination a complete transverse section through the rapidly growing callus was fixed in formaldehyde, divided into individual zones, and decalcified. Routine processing included staining with hematoxyline and eosine and elastica-van Gieson's stain. In addition, tissue samples from the diverse zones of the callus were separately decalcified and deep-frozen. Frozen 
sections were used for the localization of interstitial collagen types I, II, III, and V as described (17). Type-specific antibodies were prepared according to standard protocols (18).

Analysis of the authentic tissue. Bone compacta was carefully separated from spongiosa and periosteum, washed in $80 \%$ ethanol, homogenized, and lyophilized. Callus samples from the different regions were treated in the same way. Lyophilized samples were decalcified by dialysis at $4^{\circ} \mathrm{C}$ against $0.1 \mathrm{M}$ EDTA with repeated changes over $3 \mathrm{wk}$ and against $0.5 \%$ acetic acid for an additional $3 \mathrm{~d}$, both in the presence of proteinase inhibitors ( $20 \mu \mathrm{M}$ PMSF, $10 \mu \mathrm{M}$ 4-chlormercuribenzoate). Dry weights were determined before and after demineralization and used for the calculation of the mineral content. Two samples of $1 \mathrm{mg}$ each of the decalcified material were used for amino acid analysis after hydrolysis in $6 \mathrm{~N} \mathrm{HCl}$ under $\mathrm{N}_{2}$ atmosphere at $110^{\circ} \mathrm{C}$ for $18 \mathrm{~h}$ using an automated amino acid analyzer (model LC 5000; Fa. Biotronik GmbH, Puchheim, FRG). Generally, duplicates were analyzed. Another 2-mg aliquot was dissolved in $0.3 \mathrm{~N} \mathrm{KOH}$ by heating to $70^{\circ} \mathrm{C}$ for $1 \mathrm{~h}$. The protein content was determined according to Lowry et al. with BSA as standard (19). The DNA content of this sample was measured by the method of Burton, using salmon sperm DNA as standard (20).

For collagen extraction and fractionation, $20 \mathrm{mg}$ of demineralized bone or callus tissue, respectively, were treated with pepsin $(0.1 \mathrm{mg} / \mathrm{ml}$; $4^{\circ} \mathrm{C}$; $\mathrm{pH} \mathrm{1.8)}$ four times for $12 \mathrm{~h}$ each. The undissolved material was collected by centrifugation and the supernatants were combined. Pepsin was inactivated by raising the $\mathrm{pH}$ to 7.4 and collagen types were separated by fractionated salt precipitation. After the neutral salt precipitation collagens II and $\mathrm{V}$ were precipitated under acidic conditions (21). Aliquots of the individual fractions were analyzed by PAGE (22). In some instances the method of delayed reduction was used (23). $\mathrm{CNBr}$ cleavage ( $70 \%$ formic acid; $30^{\circ} \mathrm{C} ; 4 \mathrm{~h}$ ) was used to identify $\alpha 1$ (II) $(24,25)$. Other aliquots of the salt-fractionated collagen pools were desalted, lyophilized, and used for amino acid analysis as described above.

Analysis of cell cultures. Skin fibroblasts and callus cells were grown from skin biopsies or from callus specimens, respectively, originating from different zones of the callus (Fig. 1, $A$ and $B$ ). The cells were maintained in DME supplemented with $10 \%$ FCS, ascorbate (50 $\mu \mathrm{g} / \mathrm{ml})$, penicillin $(400 \mathrm{U} / \mathrm{ml})$, streptomycin $(50 \mu \mathrm{g} / \mathrm{ml})$, and glutamine $(2 \mathrm{mM})(26)$. In all experiments we used cells that had been passaged no more than three to five times. Callus cells did not survive freezing and thawing as a consequence of storage under liquid nitrogen.

For pulse-labeling of cell cultures, confluent cells were trypsinized, replated at a split of 2:1, and grown for $2 \mathrm{~d}$. Cells were changed to fresh medium from which streptomycin was omitted. After $24 \mathrm{~h}$ cells were incubated for another $24 \mathrm{~h}$ with $10 \mu \mathrm{Ci} / \mathrm{ml} \mathrm{L}-5-\left[{ }^{3} \mathrm{H}\right]$ proline $(15-40$ $\mathrm{Ci} / \mathrm{mmol}$; Amersham Corp., Braunschweig, FRG) in the absence of serum, streptomycin, and glutamine. The incubation medium contained fresh ascorbate $(50 \mu \mathrm{g} / \mathrm{ml})$ and $\beta$-aminopropionitrile $(100$ $\mu \mathrm{g} / \mathrm{ml}$ ) to prevent crosslinking of collagen (26). For quantitative analysis of the newly synthesized collagen, cell layer and medium proteins were separately collected and dialyzed against repeated changes of $0.5 \%$ acetic acid in the presence of protease inhibitors. Two independent experiments were carried out and the mean values were calculated. Aliquots of each collagen pool were lyophilized and hydrolyzed. The amounts of $\mathrm{L}-\left[{ }^{3} \mathrm{H}\right]$ proline and $\mathrm{L}-\left[{ }^{3} \mathrm{H}\right]$ hydroxyproline were analyzed by ion exchange chromatography and by subsequent determination of the radioactivity using scintillation counting of pooled aliquots. $\left[{ }^{3} \mathrm{H}\right]$ Proline-labeled proteins from parallel incubations were dialyzed against $0.5 \%$ acetic acid, lyophilized, dissolved in SDS-Lämmli buffer (1X), and analyzed by PAGE for the presence of precursors of collagen (27). In some instances newly synthesized collagens were subjected to limited pepsin digestion $\left(0.1 \mathrm{mg} / \mathrm{ml} ; 18^{\circ} \mathrm{C} ; 6 \mathrm{~h}\right)$ and separated by interrupted gel electrophoresis (26). Additionally, pepsin-treated collagen chains were separated by HPLC and, after lyophilization, subjected to $\mathrm{CNBr}$ cleavage ( $70 \%$ formic acid; $\left.30^{\circ} \mathrm{C} ; 4 \mathrm{~h}\right)(24,25)$. After lyophilization $\mathrm{CNBr}$-derived peptides were separated on a $12 \%$ polyacrylamide gel.

\section{Results}

\section{Morphological examination}

The histopathologic features of the callus were consistent with previous observations on hyperplastic callus $(10,11)$. The rapidly growing callus was not homogeneous but consisted of four distinct zones (Fig. 1, A and B). The outermost part of the callus (zone A) consisted of a layer of edematous tissue with atrophic muscle fibers and a loose collagenous network. Underneath, zone B showed partly mucoid edema and the proliferation of fibroblastic cells, although chondroid tissue could occasionally be seen. The neighboring zone $\mathrm{C}$ was mainly composed of chondroid and fibrochondroid tissue with multiple vascular channels surrounded by a loose connective tissue matrix. In this area there were strands of true cartilage with multiple chondrocytes. These cells showed marked nuclear
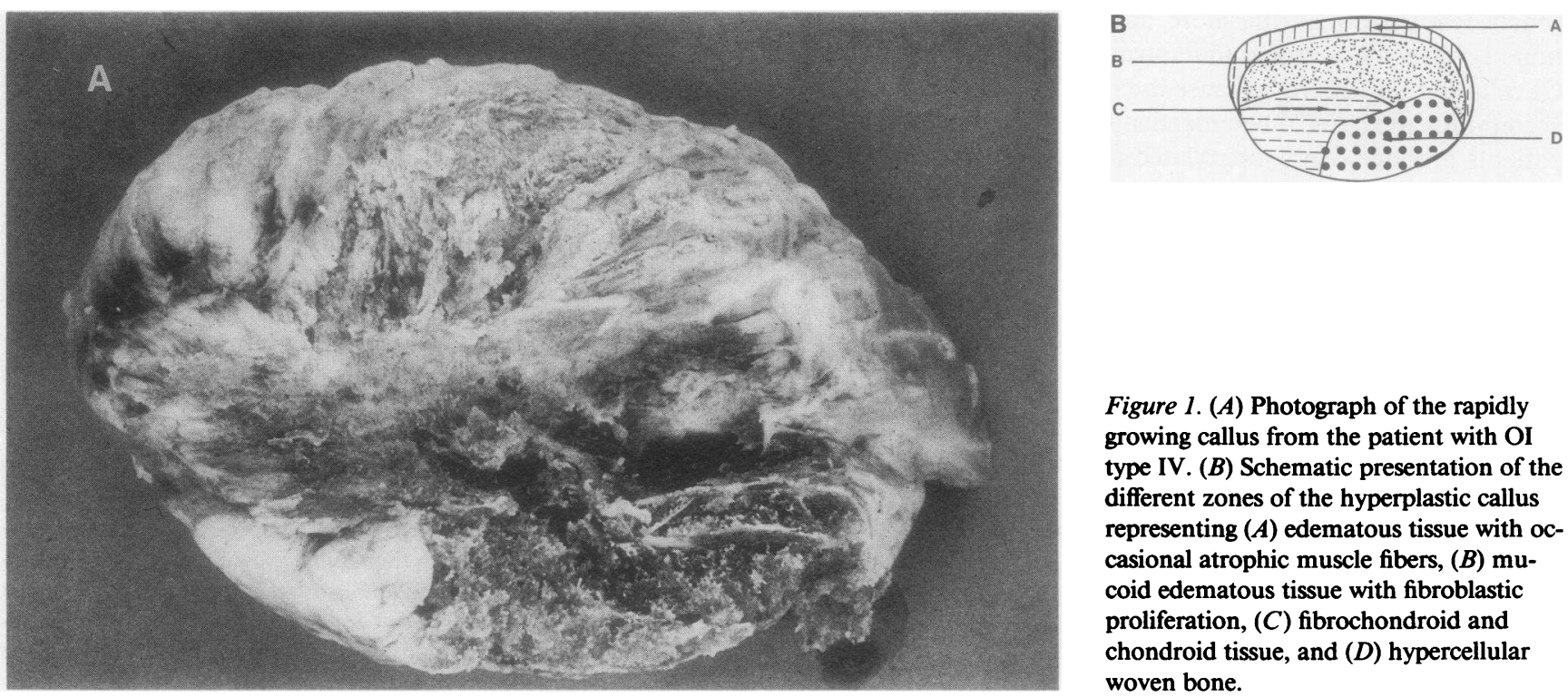

Figure 1. (A) Photograph of the rapidly growing callus from the patient with $O I$ type IV. (B) Schematic presentation of the different zones of the hyperplastic callus representing $(A)$ edematous tissue with occasional atrophic muscle fibers, $(B) \mathrm{mu}$ coid edematous tissue with fibroblastic proliferation, $(C)$ fibrochondroid and chondroid tissue, and $(D)$ hypercellular woven bone. 
polymorphism though without any anaplastic shape as seen in chondrosarcomas, for example. The innermost zone D consisted of hypercellular trabeculae mainly composed of woven bone with occasional small cartilagenous islands. In summary, the histology was typical for a rapidly proceeding mixed desmal and chondral ossification process lacking the characteristics of a malignant tumor. The histological appearance of the stationary callus closely resembled that of zone D of the growing callus. Immunohistochemical staining for collagens I, III, and $\mathrm{V}$ was found in all zones of the rapidly growing callus. Antibodies to collagen II gave a very. faint staining pattern in zones B-D (data not shown).

\section{Biochemical analysis of the authentic tissues}

Mineral content. Compact bone from both the patient and control had a mineral content of $\sim 70 \%$. The rapidly growing hyperplastic callus showed increasing mineralization from the capsule (zone A), which was not mineralized, to the center (zone D), never reaching the levels found in compact bone. Even the stationary callus, which had existed for about $5 \mathrm{yr}$, did not exceed a mineral content of $40 \%$ (Fig. 2 ).

DNA content. The DNA content per milligram dry weight after demineralization was similar in compacta from patient and control. All samples of the hyperplastic callus, however, had a markedly elevated DNA content that was highest in the central part of the growing callus and in the stationary callus (data not shown).

Protein content per cell (milligrams protein/milligram $D N A$ ). The protein content per cell was highest in control compacta, slightly lower in the patient's compacta, and substantially reduced in all callus tissues. The lowest values for protein content were found in zone $\mathrm{D}$ of the rapidly growing callus and in the stationary callus. This observation argues against the formation of a more stable bone as the callus matures (Fig. $3 A$ ).

Relative amount of collagen from total protein. Since an appropriate interaction of collagenous and noncollagenous proteins is necessary for the mechanical stability of bone, we determined their relative amounts in the different tissues by amino acid analysis. The capsule (zone $A$ ) and the central part (zone D) of the growing callus as well as the stationary callus had a proportion of collagen comparable to that of compact bone from the patient and the control. Zones B and C of the rapidly proliferating callus had markedly reduced collagen content indicating disproportionate deposition of collagenous proteins (Fig. 3 B).

Hydroxylation of collagen. Since it is known that some patients with OI have variable amounts of overhydroxylated

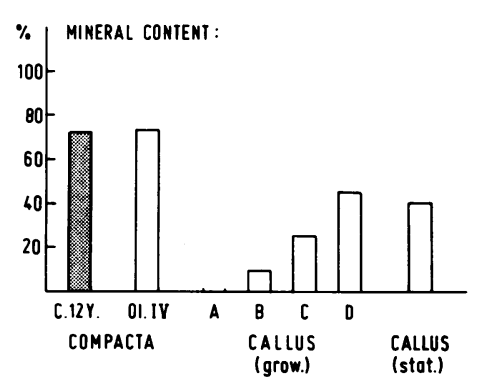

Figure 2. Histogram of the mineral content of various tissues from the bone compacta and different callus specimen of the OI patient. Compacta from an appropriate control is also shown. The differences between dry weights before and after demineralization were used to calculate the mineral content of each tissue specimen.
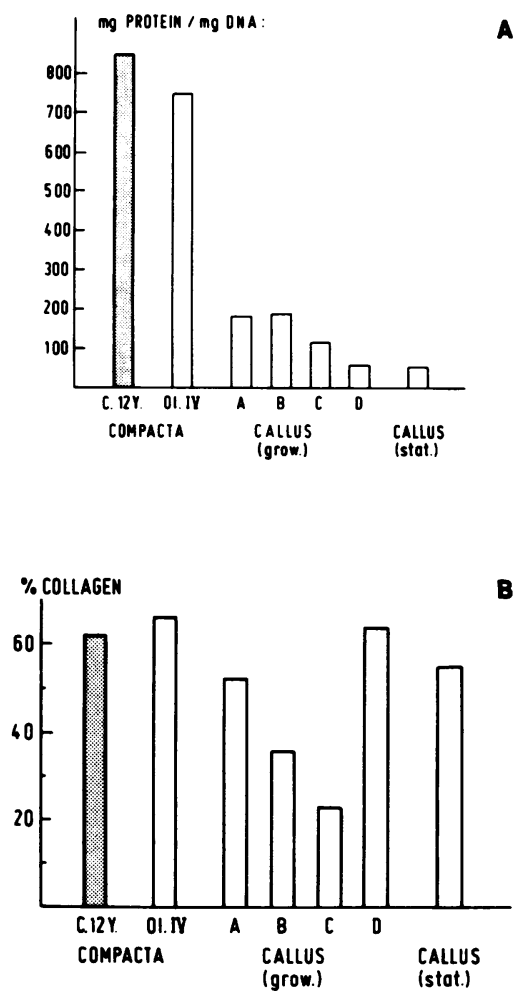

Figure 3. Histogram of the protein content $(A)$ and the relative proportion of collagen $(B)$ in various tissues from the patient and from a control.

and overglycosylated collagens, we determined the ratio between hydroxylysine and hydroxyproline as an initial measure for overmodification. In bone compacta from the patient and the control, similar values were found. In all zones of the rapidly growing callus, however, the ratio between hydroxylysine and hydroxyproline was markedly elevated. In the stationary callus the degree of lysyl hydroxylation seemed to approach the value of the compact bone (data not shown).

Since the degree of lysyl hydroxylation varies among collagen types I, II, III, and V, we separated the individual collagen types from each other by sequential salt precipitation of the pepsin-solubilized collagens and determined the rates of hydroxylysine to lysine (Table I). For identification of individual

Table I. Degree of Hydroxylation of Collagens I and III from Hyperplastic Callus and Compact Bone

\begin{tabular}{|c|c|c|c|c|}
\hline \multirow[b]{2}{*}{ Tissue } & \multicolumn{2}{|c|}{ Collagen I } & \multicolumn{2}{|c|}{ Collagen III } \\
\hline & Hyp/Pro & Hyl/Hyl + Lys & Hyp/Pro & $\mathrm{Hyl} / \mathrm{Hyl}+$ Lys \\
\hline \multicolumn{5}{|l|}{ Growing callus } \\
\hline Zone A & 0.86 & 0.382 & 1.23 & 0.405 \\
\hline Zone B & 0.92 & 0.415 & 1.20 & 0.429 \\
\hline Zone C & 0.92 & 0.615 & 1.30 & 0.432 \\
\hline Zone D & 0.84 & 0.333 & 1.22 & 0.368 \\
\hline Stationary callus & 0.84 & 0.231 & 1.08 & 0.278 \\
\hline Compacta patient & 0.85 & 0.136 & \multicolumn{2}{|c|}{ Not found } \\
\hline \multicolumn{5}{|l|}{ Compacta control } \\
\hline 6 & 0.87 & 0.135 & \multicolumn{2}{|c|}{ Not found } \\
\hline 12 & 0.85 & 0.129 & \multicolumn{2}{|c|}{ Not found } \\
\hline
\end{tabular}




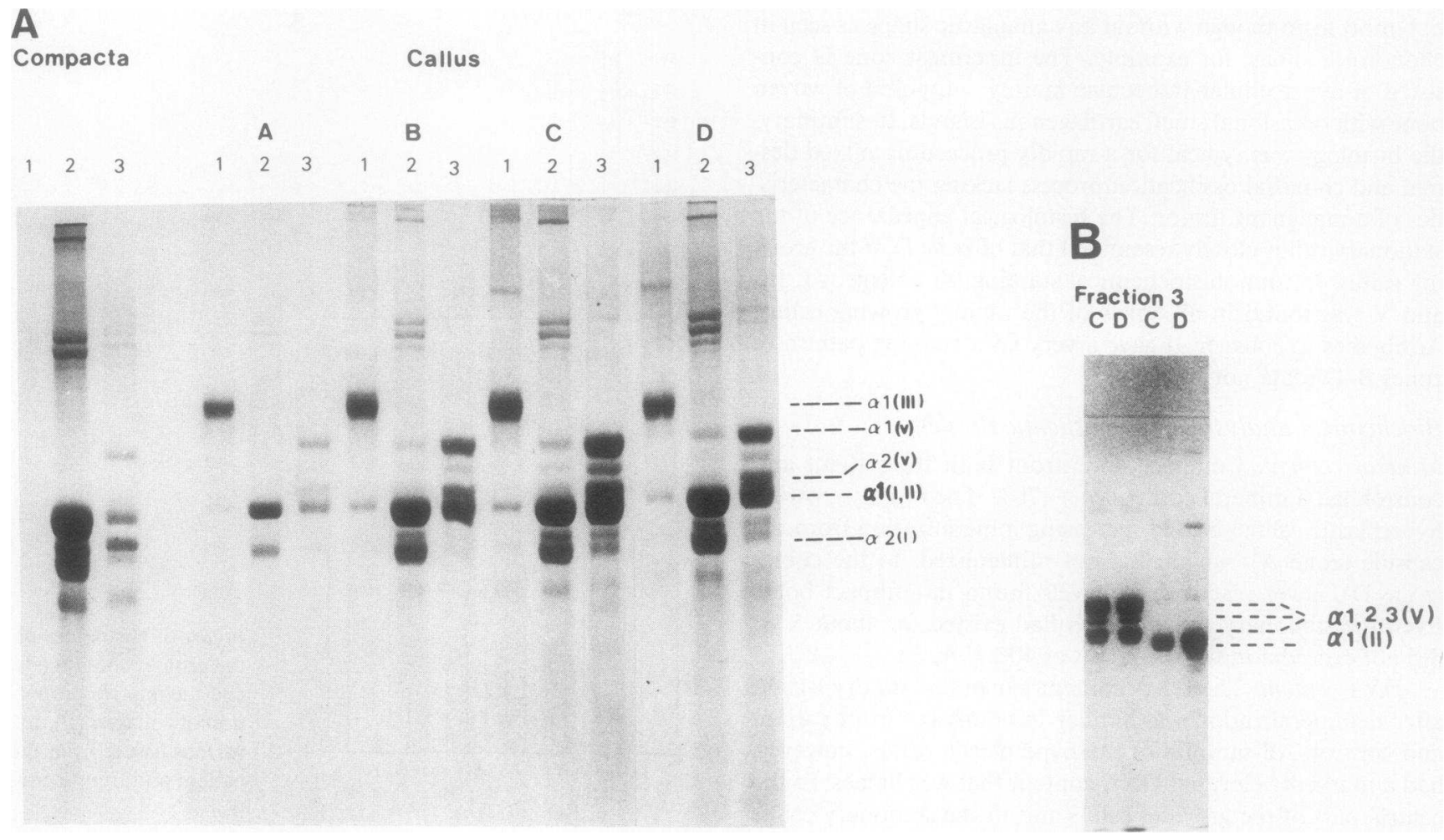

Figure 4. (A) Electropherogram of collagen types after differential salt precipitation. Collagens were solubilized from bone compacta and from the various zones of the proliferating callus by limited pepsin digestion. $A, B, C$, and $D$ represent the zones of the rapidly growing callus. ( $I$ ) Collagen precipitated with $1.5 \mathrm{M} \mathrm{NaCl}$, (2) collagen precipitated with $2.5 \mathrm{M} \mathrm{NaCl}$, (3) supernatant of the $2.5 \mathrm{M} \mathrm{NaCl}$ fractionation step. Aliquots of each pool were loaded onto polyacrylamide gels and separated using delayed reduction with mercaptoethanol. $(B)$ The supernatant of the $2.5 \mathrm{M} \mathrm{NaCl}$ fractionation step was further fractionated using acidic conditions resulting in the separation of collagen $\mathrm{V}$ from collagen II. Left lanes, collagen V from zones $\mathrm{C}$ and $\mathrm{D}$; right lanes, collagen II from zones $\mathrm{C}$ and $\mathrm{D}$.

collagen types aliquots were analyzed by PAGE (Fig. $4 \mathrm{~A}$ ). Fraction 1 contained predominantly collagen III and fraction 2 consisted almost entirely of collagen I. A band migration between $\alpha 1$ (I) and $\alpha 2$ (I) collagen chains probably represents a degradation product of the $\alpha 1$ (I) chain often seen after limited pepsin digestion. The supernatant of the $2.5 \mathrm{M}$ neutral salt precipitation (fraction 3 ) of zones $\mathrm{C}$ and D was precipitated under acidic conditions to separate collagens $\mathrm{V}$ and II (Fig. 4 $B$ ). The patterns of $\mathrm{CNBr}$-derived peptides of the collagen chain migrating as a single band were consistent with that of collagen (II) (Fig. 5). The amino acid analysis showed that both collagens I and III are overhydroxylated, and that the overmodification was most prominent in the least mature zone $\mathrm{C}$. The stationary callus revealed values that were closer to that of control compacta (Table I). Collagens II and V showed a normal degree of lysyl hydroxylation (type II, 0.52 ; type V; 0.65 for Hyl to Hyl plus Lys). The fact that the $\alpha 1$ (I) and $\alpha 2$ (I) collagen chains from the callus tissue did not migrate slower than controls may be explained best by assuming that the lysyl residues are overhydroxylated but not overglycosylated.

\section{Analysis of newly synthesized collagen from cell cultures}

To study collagen metabolism in vitro we established cell cultures from the different zones of the rapidly growing callus and compared them with skin fibroblasts from the patient and an age-matched control. We also studied cells from the stationary callus. The morphology of the callus cells was different from that of skin fibroblasts. They were larger, polygonal in shape, and more granular (not shown).

Electrophoretic separation of collagen chains and peptides. The procollagen or collagen chains, respectively, obtained either from medium or cell layer after metabolic labeling of cell cultures, did not reveal alterations in their electrophoretic mobility (Fig. 6). No double bands or tailing were observed with any collagen chain, nor was the banding pattern of the patient's collagen any different from that of controls. No double band or tailing was seen when pepsin-digested collagen was analyzed by PAGE (data not shown). To look for subtle alterations at the peptide level we separated the $\alpha 1$ (I) and $\alpha 2$ (I)

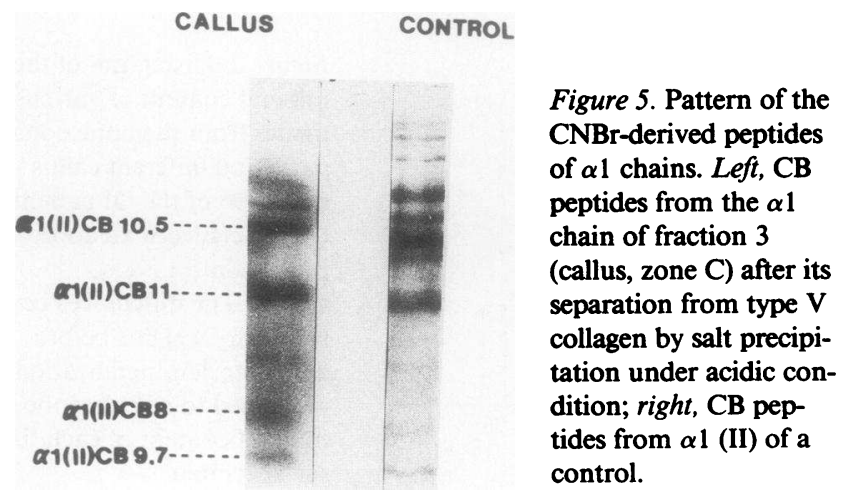




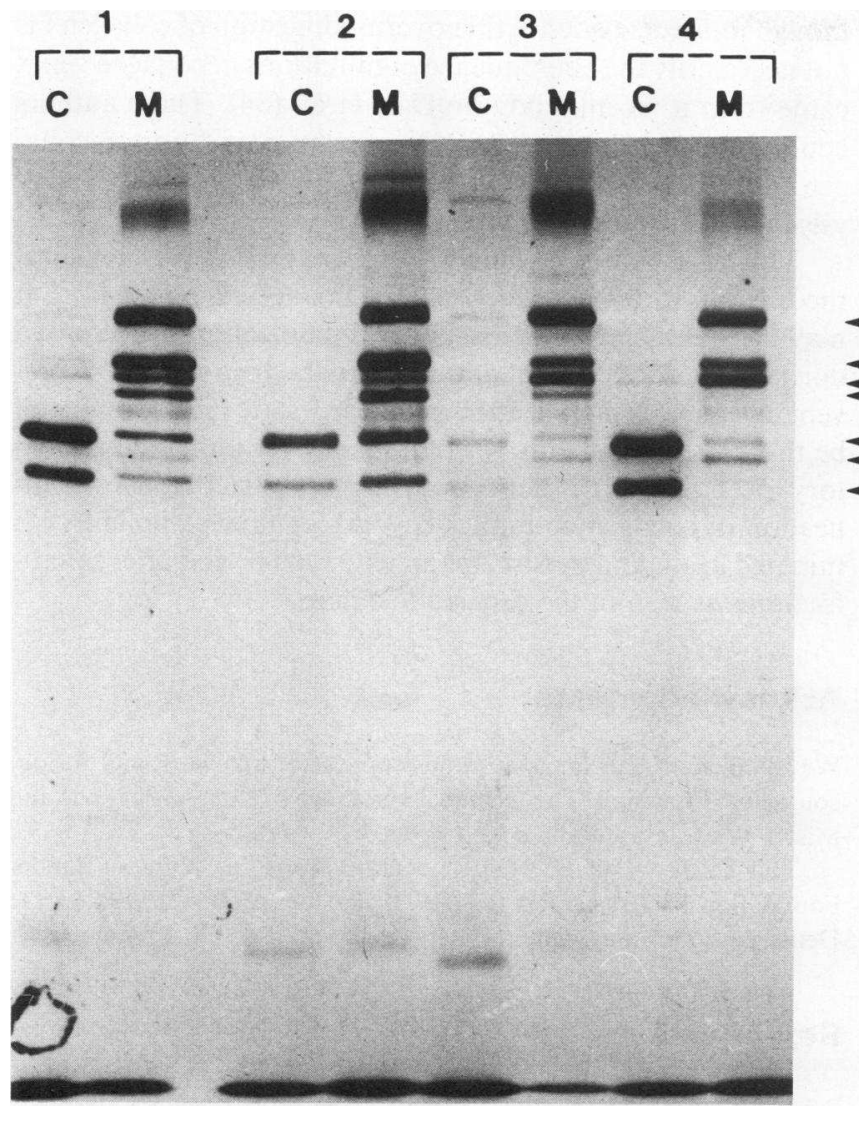

chains of type I collagen from skin fibroblasts and callus cells of the patient and the control by HPLC. The isolated $\alpha 1$ (I) chains were cleaved with $\mathrm{CNBr}$ and the resulting peptides of the $\alpha 1$ (I) were electrophoretically separated (Fig. 7). No difference in mobility upon gel electrophoresis was noted. The same experimental approach has recently been used to identify overmodified collagen in transgenic mice (28).

Quantitative analysis of the newly synthesized collagen. To look for quantitative differences in collagen synthesis the amounts of labeled proline and hydroxyproline from hydrolysates of combined cell layer plus medium proteins were deter-

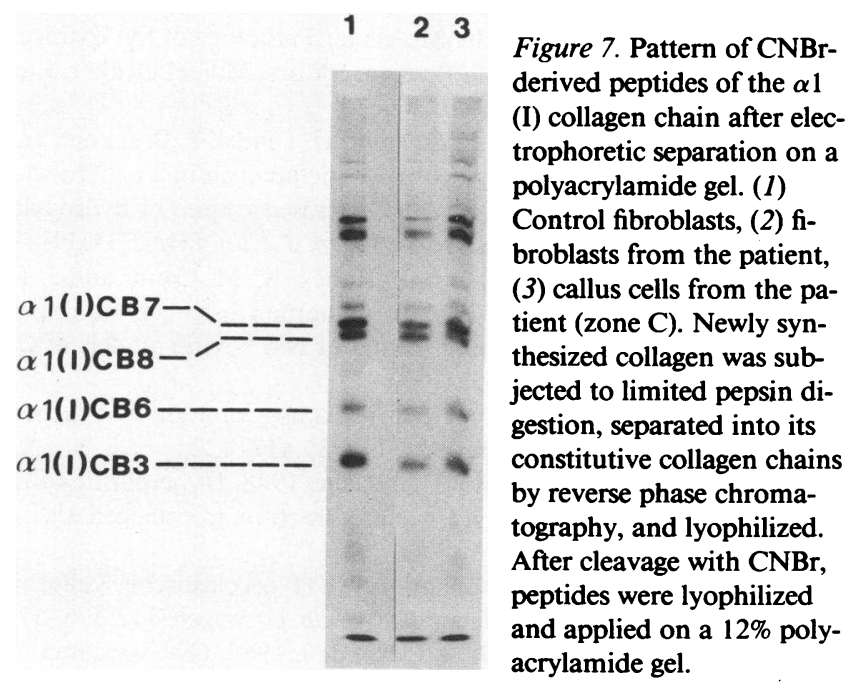

PROa $1(1)$

$\operatorname{PC} \alpha 1(1)$

PROO2(1)

PCO2IT,PNOA(I)

$\alpha 1(1)$
Figure 6. Electrophoretic separation of procollagen on a SDS-polyacrylamide gel under reducing conditions. (1) Procollagen from skin fibroblasts of the patient, (2) procollagen from callus cells obtained from zone B, (3) procollagen from callus cells obtained from zone $D,(4)$ procollagen from skin fibroblasts of a control. mined (Fig. 8). Skin fibroblasts of the patient had a slight but not statistically significant reduction of collagen synthesis (OI fibroblasts: $26,816 \mathrm{cpm}$ hydroxyproline $/ 10^{5}$ cells) compared with an age-matched control (control fibroblasts: $30,048 \mathrm{cpm}$ hydroxyproline $/ 10^{5}$ cells). Callus cells from all zones had values that exceeded those from skin fibroblasts by $300 \%$. Under the conditions applied, cultured callus cells showed a more active collagen synthesis than one would have expected from the analysis of the tissue itself where collagen content was reduced. In all instances, secretion of collagen during a 24-h pulse experiment was similar in all cell strains studied $(\sim 80 \%$ of the newly synthesized collagen was found in the medium). Synthesis of collagen as a fraction of total protein was slightly elevated in cells from the zones $\mathrm{B}$ and $\mathrm{C}$ of the rapidly growing callus. In the other zones the relative amount of collagen from total protein was in the range of control fibroblasts (data not shown).
CPM HYP/105 CELLS

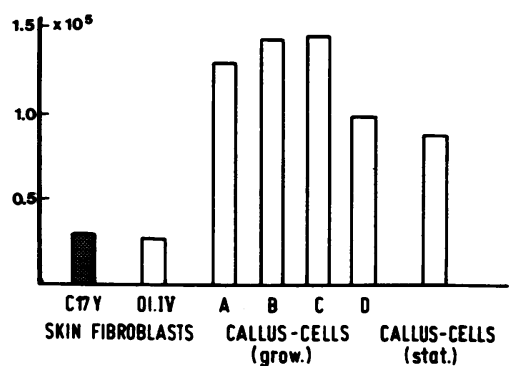

Figure 8. Histogram of the collagen synthesis in callus cells and skin fibroblasts from the OI patient and a control. Callus cells were obtained from different zones of the rapidly growing callus, as well as from callus cells of the previously removed stationary callus. 


\section{Discussion}

Hyperplastic callus formation is a striking feature of some patients suffering from $\mathrm{OI}$, in particular, those patients with white sclerae and a negative family history of OI. Furthermore, males are more often affected than females (29). The patient described here presented similar characteristics and may thus support the notion that $O I$ patients with a hyperplastic callus belong to a subgroup of $\mathrm{OI}$.

Compositional analysis of various zones of the rapidly growing hyperplastic callus confirmed the histological heterogeneity of this tissue. All zones of this callus showed poor mineralization, and even the stationary callus was insufficiently mineralized. The protein and collagen contents per cell were generally low in callus tissue, even in the central and most mature zone.

By contrast, cultured cells derived from the various zones of the hyperplastic callus exhibited an elevated synthesis of collagen when compared with control fibroblasts or fibroblasts from the skin of the same patient. This apparent discrepancy cannot be explained at present and requires additional analysis of callus tissue and callus-derived cells. Possibly circulating or tissue-specific factors exert a stringent control of the expression of collagen genes in vivo and might be lost in vitro.

The collagen synthesized by cultured callus cells does not show the retarded migration of overmodified collagen chains upon gel electrophoresis. Furthermore, no difference was noted in the migration pattern of $\mathrm{CNBr}$-derived peptides of collagen I from OI or control cells. These data imply that low collagen deposition and a high degree of overmodification in vivo are reversed to high collagen production and normal modification in vitro. There is also the possibility that the collagen newly synthesized by callus cells is overhydroxylated but not overglycosylated. Presumably overhydroxylated type I collagen would not exhibit a retarded migration.

In our analysis of tissues collagen I from compact bone of the patient was modified to a normal extent, while the same collagen type along with collagen III from callus tissue were found to be overhydroxylated. Collagens II and V showed normal levels of lysyl hydroxylation. A more detailed analysis of the individual collagen chains and their respective $\mathrm{CNBr}$-derived peptides should not only show the distribution of overmodification along the collagen chains but also clarify whether or not the callus collagens are overglycosylated. This study is currently underway. A similar degree of overmodification in collagens I and III along with normally hydroxylated collagen II has been reported for the bones of perinatal lethal OI type II $(8,30)$. Other authors, however, have also found that collagen $\mathrm{V}$ can be overmodified (31).

In a number of cases of OI overmodification of collagen type I was attributed to mutations in the corresponding collagen genes $(4-6,32,33)$. In the case of the callus tissue studied here this notion would imply that two collagen genes carry mutations in parallel. Such a conclusion, however, has only a low probability, especially since we did not find any experimental evidence in support of it. Furthermore, the level of overmodification decreases towards normal as the tissue matures (see Table I, analysis of zone D of the rapidly growing callus, stationary callus, and compact bone). Again, this normalization is difficult to reconcile with the hypothesis of a collagen mutation as the molecular defect for overhydroxylation in callus tissue of this patient with OI type IV. Additional, though indirect, evidence that overmodification of collagen I is not necessarily the consequence of mutations in collagen genes came from a recent study by Daw et al. (34). These authors could exclude a linkage of collagen overmodification to collagen I genes by restriction fragment length polymorphism analysis in a family with OI type III.

Thus, it is fair to speculate that there exists a physiological mechanism to regulate the levels of collagen modification. It may be that increased levels of overmodification are required during fetal development and perhaps fracture healing to prevent extensive mineralization at an early state (35). It may well be that in some patients with OI this as yet unknown regulatory mechanism does not operate normally, so that overmodification of collagen continues beyond fetal development or is initiated again and persists for an extended period after microfractures as seen in the case studied here.

\section{Acknowledgments}

We thank K. Kühn for continuous support of this work and for encouraging discussion. The technical assistance of Mrs. A. Pavlovic and Miss I. Wiest is gratefully acknowledged.

This study was supported by a grant from the Wilhelm Sander Foundation to Dr. Müller (83.019.2) and by a fellowship from the Deutsche Forschungsgemeinschaft (Br. 919/1-1) to Dr. Brenner.

\section{References}

1. McKusick, V. A. 1972. Osteogenesis imperfecta. In Heritable Disorders of Connective Tissue. C. V. Mosby Co., Saint Louis, MO. 390-441.

2. Smith, R., M. J. O. Francis, and G. R. Houghton. 1983. The Brittle Bone Syndrome: Osteogenesis Imperfecta. Butterworth \& Co., Ltd., London. 1-210.

3. Sillence, D. O., A. Senn, and D. M. Danks. 1979. Genetic heterogeneity in osteogenesis imperfecta. J. Med. Genet. 16:101-116.

4. Prockop, D. J., and H. Kuivaniemi. 1986. Inborn errors of collagen. Rheumatology. 10:246-271.

5. Cheah, K. S. E. 1985. Collagen gene and inherited connective tissue disease. Biochem. J. 229:287-303.

6. Byers, P. H., P. Tsipouras, J. F. Bonadio, B. J. Starman, and R. C. Schwartz. 1988. Perinatal lethal osteogenesis imperfecta (OI type II): a biochemically heterogenous disorder usually due to new mutations in the genes for type I collagen. Am. J. Hum. Genet. 42:237-248.

7. Kivirikko, K. I., and H. Kuivaniemi. 1987. Post-translational modifications of collagen and their alterations in human diseases. In Connective Tissue Disease: The Molecular Pathology of the Extracellular Matrix. J. Uitto and A. J. Perejda, editors. Marcel Dekker, Inc., New York. 263-292.

8. Kirsch, E., T. Krieg, K. Remberger, H. Fendel, P. Bruckner, and P. K. Müller. 1981. Disorder of collagen metabolism in a patient with osteogenesis imperfecta (lethal type): increased degree of hydroxylation of lysine in collagen types I and III. Eur. J. Clin. Invest. 11:39-47.

9. Fisher, L. W., M. A. Drum, P. Robey, K. M. Conn, and J. D. Termine. 1987. Osteonectin content in human osteogenesis imperfecta bone shows a range similar to that of two bovine models of OI. Calcif. Tissue Int. 40:282-285.

10. Strach, E. H. 1953. Hyperplastic callus formation in osteogenesis imperfecta. J. Bone Jt. Surg. Br. Vol. 35:417-422.

11. Fairbank, H. A. T., and S. L. Baker. 1948. Hyperplastic callus formation, with or without evidence of a fracture, in osteogenesis imperfecta. Br. J. Surg. 36:1-16.

12. Kepler, R., and K. Zhuber. 1974. Hyperplastische Kallusbildung bei Osteogenesis Imperfecta. Z. Orthop. Grenzgeb. 112:306-313.

13. Klenerman, L., and B. G. Ockenden. 1967. Osteosarcoma oc- 
curing in osteogenesis imperfecta. J. Bone Jt. Surg. Br. Vol. 49:314323.

14. Eltze, J., and K. J. Lennartz. 1969. Callus luxurians bei Osteogenesis Imperfecta unter dem Bilde eines Sarkoms. Z. Orthop. Grenzgeb. 106:463-475.

15. Lasson, U., D. Harms, and H. R. Wiedemann. 1978. Osteogenic sarcoma complicating osteogenesis imperfecta tarda. Eur. J. Pediatr. 129:215-219.

16. Rutkowsky, R., P. Resnik, and J. H. McMaster. 1979. Osteosarcoma occuring in osteogenesis imperfecta: a case report. J. Bone Jt. Surg. Am. Vol. 61:606-608.

17. Gay, S., and E. Miller. 1978. Collagen in Physiology and Pathology of Connective Tissue. Gustaf Fischer Verlag, Stuttgart. FRG. 1-110.

18. Timpl, R., G. Wick, and S. Gay. 1975. Antibodies to distinct types of collagens and procollagens and their application in immunohistology. J. Immunol. Methods. 18:165-175.

19. Lowry, O. H., N. J. Rosebrough, A. L. Farr, and R. J. Randall. 1951. Protein measurement with the Folin phenol reagent. J. Biol. Chem. 193:265-275.

20. Burton, K. A. 1956. A study of the conditions and mechanisms of the diphenylamine reaction for the colorimetric estimation of desoxyribonucleic acid. Biochem. J. 62:315-323.

21. Miller, E. J. 1984. Chemistry of the collagens and their distribution. In Extracellular Matrix Biochemistry. K. A. Piez and A. D. Reddi, editors. Elsevier Science Publishing Co., Inc., New York. 41-81.

22. Lämmli, U. K. 1970. Cleavage of structural proteins in the assembly of the head of bacteriophage T4. Nature (Lond.). 227:680685.

23. Sykes, B., B. Puddle, M. Francis, and R. Smith. 1976. The estimation of two collagens from human dermis by interrupted gel electrophoresis. Biochem. Biophys. Res. Commun. 72:1472-1480.

24. Bateman, J. F., T. Mascara, D. Chan, and W. G. Cole. 1986. Rapid fractionation of collagen chains and peptides by high-performance liquid chromatography. Anal. Biochem. 154:338-344.

25. Miller, E. J., and L. G. Lunde. 1973. Isolation and characterization of the cyanogen bromide peptides from the $\alpha 1$ (II) chain of bovine and human cartilage. Biochemistry. 12:3153-3159.
26. Layman, D. L., E. B. McGoodwin, and G. R. Martin. 1971. The nature of the collagen synthesized by cultured human fibroblasts. Proc. Natl. Acad. Sci. USA. 68:454-458.

27. Laskey, R. A., and A. D. Mills. 1975. Quantitative film detection of ${ }^{3} \mathrm{H}$ and ${ }^{14} \mathrm{C}$ in polyacrylamide gels by fluorography. Eur. $J$. Biochem. 56:335-341.

28. Stacey, A., J. Bateman, T. Choi, T. Mascara, W. Cole, and R. Jaenisch. 1988. Perinatal lethal osteogenesis imperfecta in transgenic mice bearing an engineered mutant pro- $\alpha 1$ (I) collagen gene. Nature (Lond.). 332:131-136.

29. Falvo, K. A., L. Root, and P. G. Bullough. 1974. Osteogenesis imperfecta: clinical evaluation and management. J. Bone Jt. Surg. Am. Vol. 56:783-793.

30. Kirsch, E., T. Krieg, A. Nerlich, K. Remberger, P. Meinecke, D. Kunze, and P. K. Müller. 1987. Compositional analysis of collagen from patients with diverse forms of osteogenesis imperfecta. Calcif. Tissue Int. 41:11-17.

31. Minor, R. R., T. Pihlajaniemi, D. J. Prockop, L. J. Denholm, and J. A. M. Wootton. 1984. Posttranslational overmodification of type I, type III and type V collagens in bovine and human osteogenesis imperfecta (OI). J. Cell Biol. 99:405a. (Abstr.)

32. Bonadio, J., and P. H. Byers. 1985. Subtle structural alterations in the chains of type I procollagen produce osteogenesis imperfecta. Nature (Lond.). 316:363-366.

33. Kuivaniemi, H., C. Sabol, G. Tromp, M. Sippola-Thiele, and D. J. Prockop. 1988. A 19-base pair deletion in the pro- $\alpha 2$ (I) gene of type I procollagen that causes in-frame RNA splicing from exon 10 to exon 12 in a proband with atypical osteogenesis imperfecta and in his asymptomatic mother. J. Biol. Chem. 263:11407-11413.

34. Daw, S., A. C. Nicholls, E. M. Williams, B. Sykes, and F. M. Pope. 1988. Autosomal recessive osteogenesis imperfecta: excess posttranslational modification of collagen not linked to either COL1A1 or COL1A2. J. Med. Genet. 25:275. (Abstr.)

35. Glimcher, M. J., F. Shapiro, R. D. Ellis, and D. R. Eyre. 1980. Changes in tissue morphology and collagen composition during the repair of cortical bone in the adult chicken. J."Bone Jt. Surg. Am. Vol. 62:964-973. 